\title{
Sevoflurane may be more beneficial than propofol in patients receiving endoscopic variceal ligation and endoscopic variceal sclerotherapy: A randomized, double-blind study
}

\author{
LINGHUA TANG, HUIMIN LIU, YANG WU, MEI LI, WEI LI, MENG JIANG, \\ JIABAO HOU, YING JIANG, ZHONGYUAN XIA and QINGTAO MENG \\ Department of Anesthesiology, Renmin Hospital of Wuhan University, Wuhan, Hubei 430060, P.R. China
}

Received September 25, 2016; Accepted May 31, 2017

DOI: $10.3892 /$ etm.2017.4919

\begin{abstract}
The aim of the present study was to evaluate the safety and efficacy of various general anesthesia regimens during endoscopic variceal ligation (EVL) and endoscopic variceal sclerotherapy (EVS). A total of 123 patients with American Society of Anesthesiologists physical status III and IV, aged 40-70 years, undergoing general anesthesia for EVL and EVS were randomly divided into two groups: Sevoflurane anesthesia (group $S ; n=60$ ) and propofol anesthesia (group $\mathrm{P} ; \mathrm{n}=60)$. Vital signs, particularly heart rate $(\mathrm{HR})$ and mean arterial pressure (MAP), were monitored. The designated time points were as follows: 5 min before induction (T0), and 1,5, 10, 15, 20, 25 and $30 \mathrm{~min}$ after intubation (T1, T2, T3, T4, T5, T6 and T7, respectively). Time intervals were recorded, including recovery time and extubation time. Following surgery, the observer recorded the Ramsay sedation scale (RSS) score and the visual analogue scale (VAS) score. Adverse reactions were noted. Results demonstrated that there were significant differences in MAP between the two groups at T2, T3, T5, T6 and $\mathrm{T} 7(\mathrm{P}<0.05)$. There was a significant difference in HR between the two groups at T2, T3 and T4 $(\mathrm{P}<0.05)$. Recovery time and extubation time in group $\mathrm{P}$ were significantly longer than those in group $\mathrm{S}(\mathrm{P}<0.05 ; 18.38 \pm 2.25 \mathrm{~min}$ vs. $14.57 \pm 1.04 \mathrm{~min}$ and $21.70 \pm 2.70 \mathrm{~min}$ vs. $15.83 \pm 0.88 \mathrm{~min}$, respectively). The rate of ephedrine injected was $58.3 \%$ (35/60 patients) in group P vs. $28.3 \%(17 / 60$ patients) in group $\mathrm{S}(\mathrm{P}<0.05)$. There was a significant difference in the RSS score between the two groups 5 min after extubation $(\mathrm{P}<0.05)$. VRS scores
\end{abstract}

Correspondence to: Professor Zhongyuan Xia, Department of Anesthesiology, Renmin Hospital of Wuhan University, 95 Zhang Zhidong Road, Wuhan, Hubei 430060, P.R. China

E-mail: xiazhongyuanmz@hotmail.com

Abbreviations: EVL, endoscopic variceal ligation; EVS, endoscopic variceal sclerotherapy

Key words: intravenous anesthesia, inhalational anesthesia, propofol, sevoflurane, EVL, EVS demonstrated that anesthetists and patients were significantly more satisfied with the procedure in group $\mathrm{S}$ than in group $\mathrm{P}$ $(\mathrm{P}<0.01)$. In conclusion, the superiority and special clinical value of inhalational anesthesia has been demonstrated during EVL and EVS attributed to stable hemodynamics and high quality of anesthesia recovery in the present study.

\section{Introduction}

The population of China has a high rate of chronic liver disease. For example, the prevalence of chronic hepatitis B was $7.18 \%$ in 2006 (1) and the prevalence of chronic alcoholic liver disease was 4.3-6.5\% in 2003 (2). Different from developed countries, hepatitis B is the most common disease in China (3,4). Globally, >350 million individuals suffer from chronic hepatitis B virus (HBV) infection. At the same time, there are $>12$ million hepatitis B patients in China and liver cancer and cirrhosis leads to the mortality of 240,000 individuals every year (5). Variceal hemorrhage $(\mathrm{VH})$ is a major and life-threatening complication of chronic liver disease and is associated with significant morbidity and mortality (6). However, the overall rate of survival may be improving with advances in medical technology. In the early 1980s, it was reported that the 6-week mortality following an acute variceal bleed was $40-50 \%$, with rebleeding rates of $>33 \%$. Today, overall 30 -day mortality is $15 \%$, the rebleeding rate is $26 \%$ and the 30-day mortality in those patients who do not rebleed is $7 \%(7,8)$. Mortality remains closely associated with failure to control bleeding or early rebleeding (6-8). As one of the most common and lethal complications of portal hypertension resulting from liver cirrhosis, esophagogastric variceal bleeding may lead to acute hemorrhage shock accompanied by other serious consequences, such as renal failure, infection and even death without timely treatment $(9,10)$. There are a number of methods used to treat variceal bleeding, such as vasoactive drugs, transjugular intrahepatic portosystemic shunt (TIPS) and endoscopic therapy (endoscopic injection scerotherapy, endoscopic ligation and endoscopic glue obliteration). Endoscopic treatment is the gold standard of care in the management and prophylaxis of variceal bleeding in patients with liver cirrhosis (11). Endoscopic variceal ligation (EVL) and endoscopic variceal sclerotherapy (EVS) are highly 
accepted by doctors and patients due to minimal trauma, significant effects, fast recovery and notable improvement in patient quality of life (12). Patients who require EVL or EVS often accept general anesthesia, which contains inhalational anesthesia and intravenous anesthesia (13).

Volatile anesthetics have been demonstrated to be more beneficial than propofol for postoperative liver function in cirrhotic patients receiving hepatectomy (14). Furthermore, animal studies had revealed that volatile anesthetics could induce some endogenous protective molecules in the liver (15). However, there is a lack of trials to compare the anesthetic effects of sevoflurane with that of propofol on patients receiving EVL and EVS. The present study aimed to evaluate the safety and efficacy of two general anesthesia regimens on patients receiving EVL and EVS.

\section{Patients and methods}

Experimental design and patients. The present study was designed as a double-blind, randomized, parallel-group study. The study was performed in accordance with the International Conference on Harmonization Good Clinical Practice guidelines (16) and was approved by the Ethics Committee of Renmin Hospital of Wuhan University (Wuhan, China). Written informed consent was obtained from all patients prior to initiation of the study. A total of 123 patients with an American Society of Anesthesiologists (ASA) status of III or IV (17) and liver cirrhosis scheduled for EVL or EVS were included in the present study. The patients consisted of 53 females and 70 males, aged from 40-70 years. Study exclusion criteria were as follows: i) Any malignant tumor; ii) hemorrhage shock during perioperative periods; iii) bacterial infection or encephalopathy; iv) large amounts of ascites; and v) a concomitant disease with reduced life expectancy.

In addition to the general laboratory tests, the blood samples of all patients were tested following the manufacturer's instructions for the presence of hepatitis B virus (Elecsys 2010 Immunology Analyzer; Roche AG, Basel, Switzerland), hepatitis $\mathrm{C}$ virus (Architect Anti-HCV, Abbott Core Laboratory, Abbott Park, IL, USA) and human immunodeficiency virus (Alere Determine HIV-1/2, Alere Inc., Waltham, MA, USA). A full clinical history, physical examination, electrocardiogram (ECG), chest radiograph, laboratory tests and ultrasonography were performed.

Anesthesia monitoring and methods. Patients were fasted from solid foods and clear liquids for $8 \mathrm{~h}$ before the procedure. Routine monitoring was performed during surgery, including ECG, noninvasive blood pressure (BP), pulse oxygen saturation $\left(\mathrm{SpO}_{2}\right)$ and Bispectral index (BIS; A-2000; Aspect Medical Systems, Inc., Natick, MA, USA). Heart rate (HR) and mean arterial pressure (MAP) were also recorded.

Prior to induction of anesthesia, the 123 patients were randomized into two groups by using a computer-generated random numbers table. A total of 62 patients were in group $\mathrm{P}$ (propofol group) and 61 patients were in group $\mathrm{S}$ (sevoflurane group). The mean of the last three vital sign measurements prior to induction was the baseline in all patients. All patients received $0.06 \mathrm{mg} / \mathrm{kg}$ intravenous tropisetron (Southwest Pharmaceutical Co., Ltd., Chongqing, China) to prevent nausea and vomiting. Anesthesia was induced with intravenous cisatracurium $(0.2 \mathrm{mg} / \mathrm{kg}$; Jiangsu Hengrui Medicine Co., Ltd., Lianyungang, China). Etomidate $(0.2 \mathrm{mg} / \mathrm{kg}$; Jiangsu Nhwa Pharmaceutical Co., Ltd., Xuzhou, China) was administered intravenously 2 min later. Remifentanil $(2 \mu \mathrm{g} / \mathrm{kg}$; Yichang Humanwell Pharmaceutical Co., Ltd., Yichang, China) and tramadol (1 mg/kg, Grunenthal GmbH, Aachen, Germany) were also administered intravenously 1 min later. On loss of consciousness and when Observer's Assessment of Alertness and Sedation score was $\leq 3$ (18), breathing was manually supported and tracheal intubation was performed by an attending doctor, which was completed within $30 \mathrm{sec}$. Following tracheal intubation, the lungs were mechanically ventilated, with volume-controlled ventilation at $6-8 \mathrm{ml} / \mathrm{kg}$ and $12 \mathrm{bpm}$. End-tidal carbon dioxide tension was maintained at $35-40 \mathrm{mmHg}$. Intravenous fluid management included administration of lactated Ringer's solution (Shandong Qidu Pharmaceutical Co., Ltd., Shandong, China). Fluid deficit was calculated to be replaced over $8 \mathrm{~h}$, and maintenance fluid was calculated according to patients' weights.

Anesthesia was maintained with intravenous $4-6 \mu \mathrm{g} / \mathrm{kg} / \mathrm{h}$ propofol (Beijing Fresenius Kabi Pharmaceutical Co., Ltd., Beijing, China) by a micropump (Syringe Infusion Pump Model 500, Wuhan Sanfeng Medical Equipment Co., Ltd., Wuhan, China) in group P and 1-1.5\% sevoflurane (Abbott Core Laboratory) by inhalation in group $\mathrm{S}$. The concentration of sevoflurane and propofol during the surgery were adjusted by the BIS monitor, which was maintained between 45 and 55 (19). Fresh $\mathrm{O}_{2}$ gas flow of $2.0 \mathrm{l} / \mathrm{min}$ was given. Remifentanil (4-6 $\mu \mathrm{g} / \mathrm{kg} / \mathrm{h}$ ) was continuously infused and controlled by a micropump (Syringe Infusion Pump Model 500). At the end of the surgery, $\mathrm{O}_{2}$ flow rate was increased to $6 \mathrm{l} / \mathrm{min}$ and the anesthetic regimens were discontinued. The endotracheal tube was removed when patients' consciousness recovered and respiration was regular and adequate in rate and depth. Boluses of ephedrine or atropine were given if hemodynamic events occurred.

Observed parameters. The designated time points for recording were as follows: The mean of the last three recordings on the vital sign monitor prior to induction was set as the baseline in all patients (T0), and 1, 5, 10, 15, 20, 25 and 30 min after intubation (T1, T2, T3, T4, T5, T6 and T7, respectively). Hemodynamic variables were recorded every min. Hemodynamic events were defined as hypotension (systolic pressure $<90 \mathrm{mmHg}$ ) and bradycardia $(\mathrm{HR}<50 \mathrm{bpm})$.

Recovery time was defined as the time between anesthetic agent discontinuation and eyes opening (either spontaneously or due to verbal commands). The endotracheal tube was removed when patients' consciousness recovered and respiration was regular and adequate in rate and depth (frequency $>8 \mathrm{bpm}$; tidal volume $>6 \mathrm{ml} / \mathrm{kg}$ ). Extubation time (time from when anesthesia administration was stopped to when the endotracheal tube was removed) was recorded.

A total of 5 min after extubation, the Ramsay sedation scale (RSS) (20) score was also measured. The RSS scores were as follows: 1 , anxious, agitated or restless; 2 , cooperative, oriented and tranquil; 3 , drowsy but responsive to stimulus; 4 , brisk response to stimulus; 5 , sluggish response to stimulus; and 6 , no response to painful stimulus. The goal of sedation in 


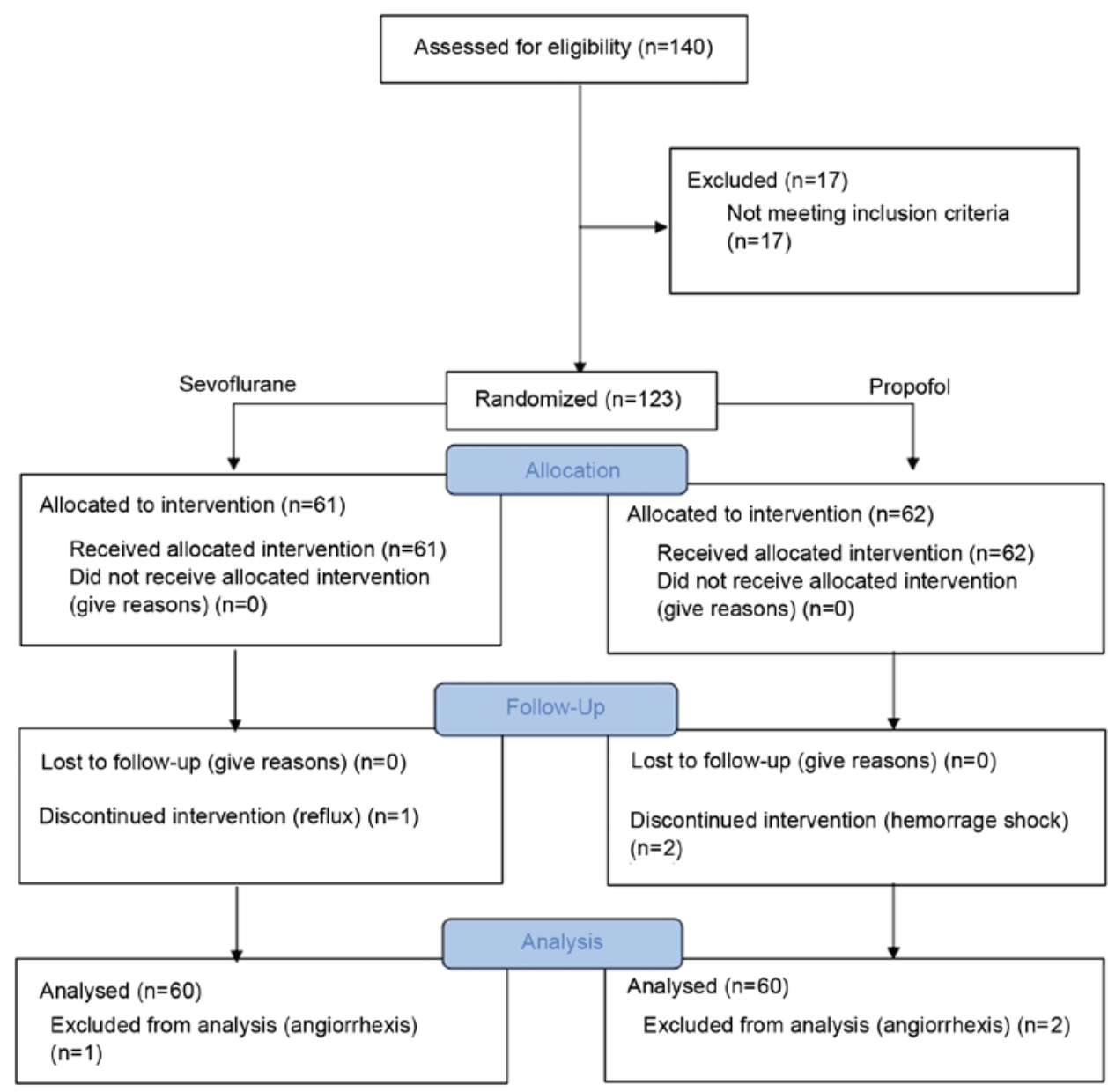

Figure 1. Flow diagram of the phases of the present randomized trial.

the present study was to limit the RSS to a score of 2-3 (20). The visual analogue scale (VAS) score (21) was also measured.

Complications during and after surgery, including hypotension, bradycardia, apnea, hypoxemia $\left(\mathrm{SpO}_{2}<90 \%\right)$ and dizziness were observed. Postoperative nausea or vomiting (PONV), awareness during surgery and postoperative delirium were also recorded.

Patient satisfaction questionnaire. If full recovery was reconfirmed in the inpatient setting, the anesthetists completed a questionnaire, by using a verbal rating scale (VRS) that inquired about i) overall satisfaction with sedation, ii) difficulty of sedation, iii) patient cooperation and iv) overall satisfaction with the procedure. All patients also completed a questionnaire by using a VRS with the following scores: 0, excellent; 1, good; 2 , fair; 3 , dissatisfied; and 4, very dissatisfied overall with the procedure, due to factors such as pain, awakening, memory and uncomfortable symptoms during recovery.

Statistical analysis. Measured data were expressed in the form of the mean \pm standard deviation. SPSS 13.0 statistical software (SPSS, Inc., Chicago, IL, USA) was used to set up the database and to calculate the results. The patient demographics (age and BMI) and surgical data were compared using unpaired t-test, analysis of variance followed by Tukey's multiple comparison tests were used to compare the vital signs at different points in the same groups and Bonferrroni post-tests were used to compare the vital signs between two groups. The chi-square or Fisher's test were used to compare the patient demographics (sex and ASA physical status) the complications between two groups. The degree of satisfaction was compared with Mann-Whitney U test between two groups. $\mathrm{P}<0.05$ was considered to indicate a statistically significant difference.

\section{Results}

Patients. A total of 140 patients were assessed for study eligibility. Of these patients, $17 \mathrm{did}$ not meet the inclusion criteria and so 123 patients were finally enrolled. During anesthesia, 1 patient experienced vascular rupture in group $S$ prior to intubation, which led to reflux aspiration. In group $\mathrm{P}, 2$ patients experienced vascular rupture during surgery. Despite the fact that following treatment for vascular rupture the prognosis was good, all of these patients were excluded. Therefore, 120 patients were finally included in the statistical analysis (Fig. 1). Patient data, basal BP, HR were similar in the two groups at T0 $(\mathrm{P}>0.05$; Table I).

Hemodynamic variables. Results demonstrated that there was a significant decrease in HR and MAP following induction of anesthesia in all patients. Compared with T1, 
Table I. Patient demographics.

\begin{tabular}{lccr}
\hline & \multicolumn{2}{c}{ Group } & \\
\cline { 2 - 3 } Variable & $\mathrm{P}(\mathrm{n}=60)$ & $\mathrm{S}(\mathrm{n}=60)$ & P-value \\
\hline Age, years & $60.6 \pm 8.35$ & $58.8 \pm 9.35$ & 0.17 \\
Sex (male/female), $\mathrm{n}$ & $25 / 35$ & $27 / 33$ & 0.71 \\
Body mass index & $19.79 \pm 1.15$ & $19.59 \pm 1.12$ & 0.32 \\
American Society of & $48 / 12$ & $50 / 10$ & 0.63 \\
Anesthesiologists & & & \\
status (III/IV), $\mathrm{n}$ & & & \\
\end{tabular}

Data are expressed as the mean \pm standard deviation where appropriate. S, sevoflurane; P, propofol.

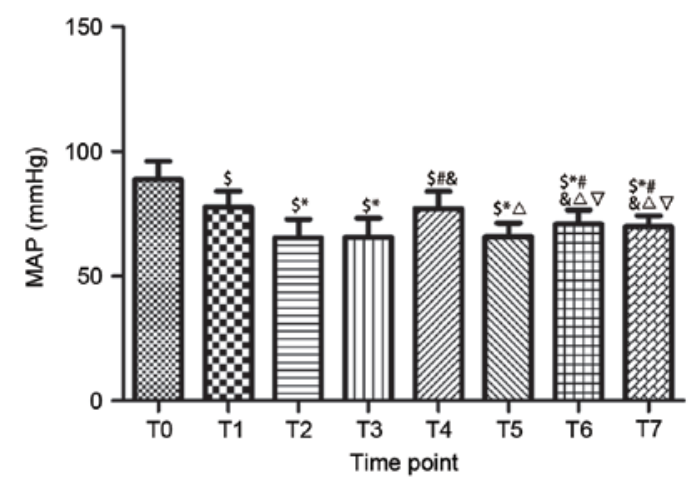

Figure 2. MAP of group $\mathrm{P}$ at different time points. MAP of group $\mathrm{P}$ was significantly decreased at all time points after induction compared with the baseline (T0). Compared with T1, MAP was lower at T2, T3, T5, T6, T7; Compared with T2, MAP was elevated at T4, T6, T7; compared with T3, MAP was elevated at T4, T6, T7; compared with T4, MAP was decreased at T5, T6, T7; compared with T5, MAP was elevated at T6, T7. Data are presented as the mean + standard deviation. ${ }^{\$} \mathrm{P}<0.05$ vs. T0; ${ }^{*} \mathrm{P}<0.05$ vs. $\mathrm{T} 1$ ${ }^{\sharp} \mathrm{P}<0.05$ vs. T2; ${ }^{\&} \mathrm{P}<0.05$ vs. T3; ${ }^{\Delta} \mathrm{P}<0.05$ vs. T4; ${ }^{\mathrm{P}}<0.05$ vs. T5. MAP, mean arterial pressure; group $\mathrm{P}$, propofol group; $\mathrm{T}$, time point.

MAP was significantly decreased at $\mathrm{T} 2, \mathrm{~T} 3, \mathrm{~T} 5, \mathrm{~T} 6$ and $\mathrm{T} 7$; Compared with T2, MAP was significantly elevated at T4, T6 and T7; compared with T3, MAP was significantly elevated at $\mathrm{T} 4, \mathrm{~T} 6$ and $\mathrm{T} 7$; compared with T4, MAP was significantly decreased at T5, T6 and T7; compared with T5, MAP was significantly elevated at T6 and T7 $(\mathrm{P}<0.05$; Fig. 2). There were significant differences in MAP in group $\mathrm{S}$ between T1 and T5, T1 and T6, T4 and T5, T4 and T6, and T4 and T7 after induction ( $\mathrm{P}<0.05$; Fig. 3). Compared with group P, MAP was significantly higher in group $\mathrm{S}(\mathrm{P}<0.05)$, except for at $\mathrm{T} 0, \mathrm{~T} 1$ and T4 (Fig. 4).

Compared with T0, HR was significantly decreased at T1, T2, T3, T5, T6 and T7; Compared with T1, HR was significantly decreased at $\mathrm{T} 2, \mathrm{~T} 3, \mathrm{~T} 6$ and $\mathrm{T} 7$ but significantly increased at T4; Compared with T2, HR was significantly elevated at T4, T5, T6 and T7; Compared with T3, HR was significantly elevated at T4, T5, T6 and T7; Compared with $\mathrm{T} 4$, HR was significantly decreased at $\mathrm{T} 5, \mathrm{~T} 6$ and $\mathrm{T} 7(\mathrm{P}<0.05$; Fig. 5). There were significant differences in HR in group $S$ between $\mathrm{T} 0$ and all other time points $(\mathrm{P}<0.05$; Fig. 6). There were significant differences in HR between the two groups at

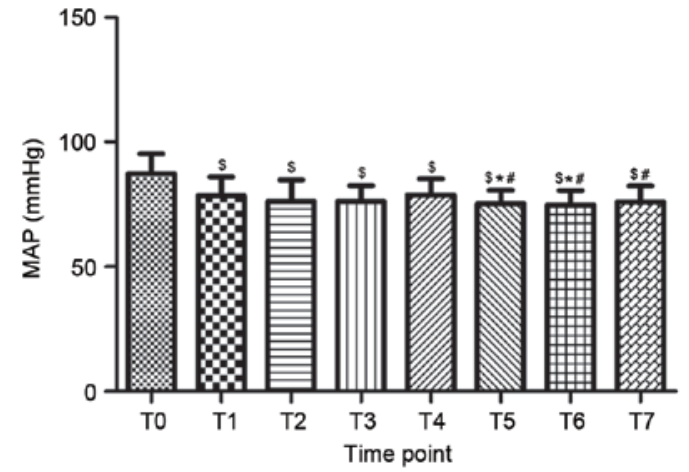

Figure 3. MAP of group S at different time points. MAP of group S was significantly decreased at all time points after induction compared with the baseline (T0). There were significant differences in MAP in group $\mathrm{S}$ between $\mathrm{T} 1$ and $\mathrm{T} 5, \mathrm{~T} 1$ and $\mathrm{T} 6, \mathrm{~T} 4$ and $\mathrm{T} 5, \mathrm{~T} 4$ and $\mathrm{T} 6$, and $\mathrm{T} 4$ and $\mathrm{T} 7$ after induction. Data are presented as the mean + standard deviation. ${ }^{\mathrm{S}} \mathrm{P}<0.05$ vs. T0; ${ }^{\text {"P }}<0.05$ vs. T1; ${ }^{\text {} P} \mathrm{P}<0.05$ vs. T4. MAP, mean arterial pressure; group $\mathrm{S}$, sevoflurane group; $\mathrm{T}$, time point.

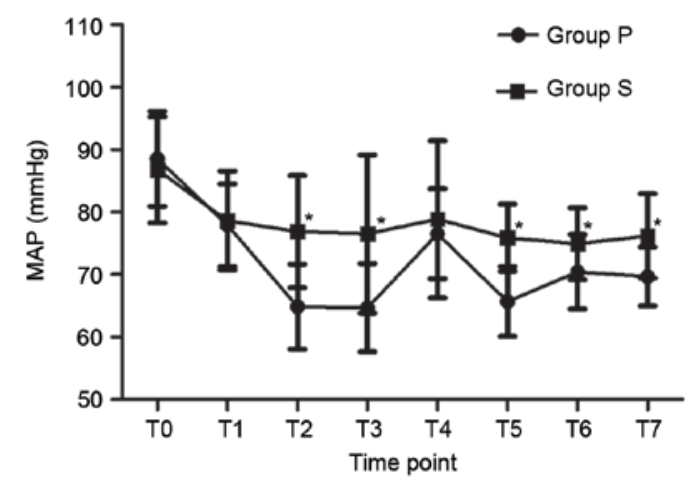

Figure 4. Comparison of MAP in groups $\mathrm{P}$ and $\mathrm{S}$. Compared with group $\mathrm{P}$, MAP was significantly higher in group S, except for at T0, T1 and T4. Data are expressed as the mean \pm standard deviation. ${ }^{*} \mathrm{P}<0.05$ vs. group P. MAP, mean arterial pressure; group $\mathrm{S}$, sevoflurane group; group P, propofol group; $\mathrm{T}$, time point.

T2-T4. At T2 and T3, HR was significantly decreased in group $\mathrm{P}$ than in group $\mathrm{S}(\mathrm{P}<0.05)$; however, at $\mathrm{T} 4$, HR was significantly decreased in group $\mathrm{S}$ than in group $\mathrm{P}(\mathrm{P}<0.05$; Fig. 7$)$.

Recovery time in group $\mathrm{P}$ was $18.38 \pm 2.25 \mathrm{~min}$ vs. $14.57 \pm 1.04$ min in group $\mathrm{S}(\mathrm{P}<0.05)$. Extubation time in group $\mathrm{P}$ was $21.70 \pm 2.70 \mathrm{~min}$ vs. $15.83 \pm 0.88 \mathrm{~min}$ in group $\mathrm{S}(\mathrm{P}<0.01$; Table II). The RSS score was significantly higher in group $\mathrm{P}$ than in group $\mathrm{S}(2.42 \pm 0.50$ vs. $2.12 \pm 0.32$, respectively; $\mathrm{P}<0.05)$ 5 min after extubation (Table II). The VAS scores given by the patients in the two groups were not significantly different $(\mathrm{P}>0.05$; Table II $)$.

Complications during surgery and following extubation. The rate of ephedrine injected was significantly higher in group P than in group S [58.3\% (35/60 patients) vs. $28.3 \%$ (17/60 patients)], respectively $(\mathrm{P}<0.05$; Table III). The occurrence of $\mathrm{SpO}_{2}<90 \%$ was significantly higher in group $\mathrm{P}(9.7 \%)$ than that in group $\mathrm{S}(0 \%$; $\mathrm{P}<0.05$; Table III). The occurrence of dizziness in group $\mathrm{P}$ was significantly higher than that in group $\mathrm{S}(\mathrm{P}<0.05 ; 13.3$ vs. $0 \%$, respectively). There were no significant differences between the two 


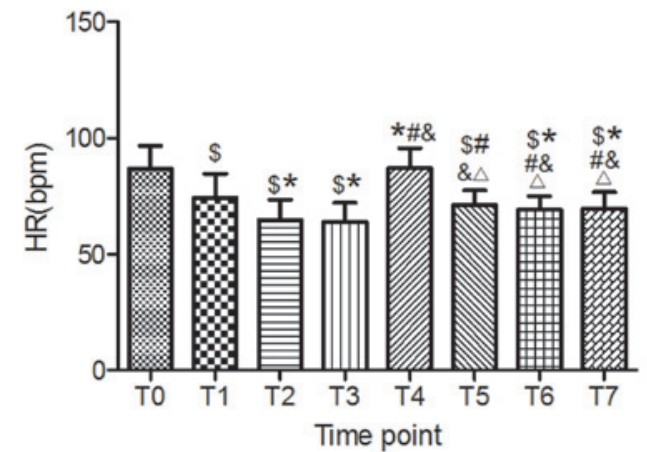

Figure 5. HR of group P at different time points. HR of group P was significantly decreased at all time points after induction compared with the baseline (T0), except for at T4. Compared with T1, HR was lower at T2, T3, T6, T7 but higher at T4; Compared with T2, HR was higher at T4, T5, T6 and T7. Compared with T3, HR was elevated at T4, T5, T6, T7; Compared with T4 HR was decreased at T5, T6, T7. Data are presented as the mean + standard deviation. ${ }^{\$} \mathrm{P}<0.05$ vs. T0; ${ }^{\mathrm{P}}<0.05$ vs. $\mathrm{T} 1 ;{ }^{*} \mathrm{P}<0.05$ vs. $\mathrm{T} 2$; ${ }^{\circledR} \mathrm{P}<0.05$ vs. T3; ${ }^{\Delta} \mathrm{P}<0.05$ vs. T4. HR, heart rate; group $\mathrm{P}$, propofol group; T, time point.

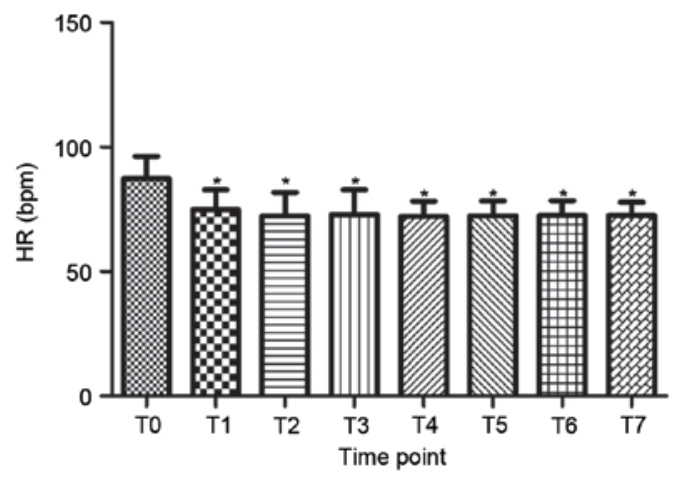

Figure 6. HR of group $\mathrm{S}$ at different time points. HR of group $\mathrm{S}$ was significantly decreased at all time points after induction compared with the baseline (T0). Data are presented as the mean + standard deviation. ${ }^{*} \mathrm{P}<0.05$ vs. T0 HR, heart rate; group S, sevoflurane group; T, time point.

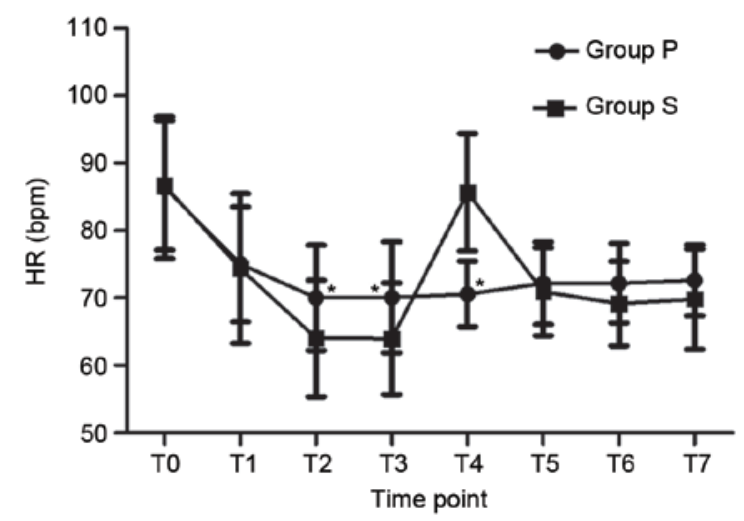

Figure 7. Comparison of HR in groups $\mathrm{P}$ and $\mathrm{S}$. There were significant differences in HR between the two groups at T2-T4. Data are presented as the mean \pm standard deviation. ${ }^{*} \mathrm{P}<0.05$ vs. group $\mathrm{S}$. HR, heart rate; group $\mathrm{S}$, sevoflurane group; group $\mathrm{P}$, propofol group; T, time point.

groups in the occurrence of PONV (6.7\% in group P vs. $10 \%$ in group $S$ ), awareness during surgery and postoperative delirium $(\mathrm{P}>0.05$; Table III).
Anesthetist and patient satisfaction. The VRS score by the anesthetists and the patients between the two groups were significantly different $(\mathrm{P}<0.01$; Table IV). The number of VRS scores of 0 and 1 given by patients and anesthetists was significantly higher in group $\mathrm{S}$ than in group $\mathrm{P}(\mathrm{P}<0.01)$. The number of VRS scores of 3 and 4 given by patients and anesthetists was significantly higher in group $\mathrm{P}$ than in group $\mathrm{S}(\mathrm{P}<0.01)$. Notably, the main reasons for their dissatisfaction were the complications listed in Table III.

\section{Discussion}

The ideal non-operating room anesthesia should ensure that the patient falls to sleep rapidly, the sedation is sufficient, the circulation is steady, the recovery is quick and that there are minimized complications (22). The results of the present study demonstrated hemodynamic stability, minimal respiratory depression and minimized complications for patients undergoing EVL and EVS when using sevoflurane. The findings of the present study demonstrated the unique characteristics of sevoflurane on minimal respiratory depression, reduced side effects, rapid recovery of awareness and high levels of satisfaction provided compared with the use of propofol.

Partially due to its rapid recovery profile, propofol is currently the most frequently used intravenous anesthetic (23). However, the most notable undesirable effect of propofol is its marked depression on cardiovascular and respiratory parameters, particularly for patients with liver cirrhosis or shock, elderly patients and patients with an ASA status of III or IV $(24,25)$. The crucial question is how to maintain the stability of hemodynamics during the perianesthesia phase. Of all currently used anesthetics, the pharmacokinetic properties of sevoflurane come closest to that of the ideal anesthetic. That the pharmacological characteristics of sevoflurane include inherent stability, low flammability, lack of irritation to airway passages, low blood: gas solubility allowing rapid induction and emergence from anesthesia, minimal cardiovascular and respiratory side effects and mimimal end-organ effects $(26,27)$, means it has a wider margin of safety for patients with marked risk factors, including an ASA III/IV status and being elderly.

The aim of the present prospective study was to determine, in a series of consecutive patients with liver cirrhosis and an ASA status of III or IV, the safety, efficacy and the satisfaction of the use of propofol and sevoflurane. Furthermore, the present study aimed to evaluate the advantage on the post-sedation activity of patients who underwent EVL and EVS with propofol anesthesia compared with patients who received sevoflurane anesthesia.

Hypotension is a common side effect associated with propofol use due to vasodilation and negative inotropic effect $(28,29)$. The present study demonstrated that, compared with propofol, sevoflurane kept hemodynamics stable. MAP and HR had smaller fluctuations in patients in group $S$ than those in group P. Patients for EVL and EVS in the current study often have acute or chronic blood loss. Propofol may be associated with diminished myocardial contractility, decreased cardiac output, reduced ability of the cardiovascular system to respond to stress (30) and preoperative fasting, all of which lead to relative or absolute hypovolemia (31). Therefore, in the present study, more ephedrine was used in group P than 
Table II. Surgical data for each group.

\begin{tabular}{lrr}
\hline & \multicolumn{2}{c}{ Group } \\
\cline { 2 - 3 } Variable & $\mathrm{P}(\mathrm{n}=60)$ & $\mathrm{S}(\mathrm{n}=60)$ \\
\hline Anesthesia time, min & $107.6 \pm 9.5$ & $109.1 \pm 9.9$ \\
Recovery time, min & $18.38 \pm 2.25$ & $14.57 \pm 1.04^{\mathrm{a}}$ \\
Time to extubation, min & $21.70 \pm 2.70$ & $15.83 \pm 0.88^{\mathrm{b}}$ \\
Ramsay sedation scale score & $2.42 \pm 0.50$ & $2.12 \pm 0.32^{\mathrm{a}}$ \\
VAS score & $2.0 \pm 0.40$ & $2.1 \pm 0.30$ \\
\hline
\end{tabular}

Data are presented as the mean \pm standard deviation. ${ }^{\mathrm{a}} \mathrm{P}<0.05$ and ${ }^{\mathrm{b}} \mathrm{P}<0.01$ vs. group P. VAS, visual analogue scale; $\mathrm{S}$, sevoflurane; $\mathrm{P}$, propofol.
Table III. Occurrence of complications in each group.

\begin{tabular}{lcc}
\hline & \multicolumn{2}{c}{ Group } \\
\cline { 2 - 3 } Complication & $\mathrm{P}(\mathrm{n}=60)$ & $\mathrm{S}(\mathrm{n}=60)$ \\
\hline Rate of ephedrine & 35 & $17^{\mathrm{a}}$ \\
Pulse oxygen saturation $<90 \%$ & 7 & $0^{\mathrm{a}}$ \\
Dizziness & 8 & $0^{\mathrm{a}}$ \\
Postoperative nausea or vomiting & 4 & 6 \\
Awareness during surgery & 0 & 0 \\
Postoperative delirium & 0 & 0 \\
\hline
\end{tabular}

${ }^{\mathrm{a}} \mathrm{P}<0.05$ vs. group $\mathrm{P} . \mathrm{S}$, sevoflurane; $\mathrm{P}$, propofol.

Table IV. Satisfaction score awarded by anesthetists and patients for the procedure.

\begin{tabular}{|c|c|c|c|c|c|}
\hline \multirow[b]{3}{*}{ Scale } & \multirow[b]{3}{*}{$\begin{array}{l}\text { Verbal rating } \\
\text { scale score }\end{array}$} & \multicolumn{4}{|c|}{ Individuals awarding score } \\
\hline & & \multicolumn{2}{|c|}{ Anesthetists } & \multicolumn{2}{|c|}{ Patients } \\
\hline & & $\begin{array}{c}\text { Group P } \\
(n=60)\end{array}$ & $\begin{array}{l}\text { Group } S \\
(n=60)\end{array}$ & $\begin{array}{l}\text { Group P } \\
(n=60)\end{array}$ & $\begin{array}{c}\text { Group S } \\
(n=60)\end{array}$ \\
\hline Excellent & 0 & 6 & $10^{\mathrm{a}}$ & 7 & $10^{\mathrm{a}}$ \\
\hline Good & 1 & 12 & $30^{\mathrm{a}}$ & 18 & $35^{\mathrm{a}}$ \\
\hline Fair & 2 & 21 & $15^{\mathrm{a}}$ & 17 & $10^{\mathrm{a}}$ \\
\hline Dissatisfied & 3 & 16 & $5^{\mathrm{a}}$ & 13 & $5^{\mathrm{a}}$ \\
\hline Very dissatisfied & 4 & 5 & $0^{\mathrm{a}}$ & 5 & $0^{\mathrm{a}}$ \\
\hline
\end{tabular}

Ranked data were analyzed using the Mann-Whitney U test. ${ }^{a} \mathrm{P}<0.01$ vs. group P. S, sevoflurane; P, propofol.

in group S. Following fluid infusion and ephedrine injection, patients' MAP was gradually increased and began to stabilize. The maintenance of MAP was better with sevoflurane compared with propofol. Although the difference may be of limited significance for healthy patients, the relative hypotension associated with propofol may be detrimental in elderly patients and patients with coronary artery disease (32-35).

A predominant aim of management for patients undergoing EVL and EVS is to minimize risk factors of myocardial and cerebral ischemia. In order to effectively reduce the likelihood of potential adverse neurological or cardiovascular events, it is essential to maintain adequate cerebral perfusion and continually adjust cardiovascular variables (36). The majority of clinicians aim to maintain arterial BP as close to the preoperative level as possible $(37,38)$. During the perioperative phase, episodes of ischemia occur in close association with marked fluctuations in BP (36). From the present study, it may be concluded that the maintenance of anesthesia with sevoflurane in patients resulted in more stable hemodynamics, but a less substantial decrease in MAP in comparison with propofol. Research has demonstrated that propofol induces a reduction in BP and HR in humans (39), and inhibition of sympathetic nerve activity is believed to be one of the major mechanisms underlying propofol-induced hemodynamic depression (38). These results are similar to those of the present study.

The present study demonstrated that the recovery time and extubation time in group $\mathrm{S}$ were significantly shorter than those in group P. Furthermore, there was less individual variation between patients in the recovery time or extubation time in group $S$ than in group P. Patients undergoing EVL and EVS usually have low serum albumin levels and hypovolemia due to liver dysfunction and bleeding $(40,41)$. Compared with propofol, sevoflurane is metabolized independent of liver and renal function; therefore, it is more controllable (42).

The present study also demonstrated that the RSS score of patients 5 min after extubation in group $\mathrm{S}$ was significantly lower than that in group P. As a non-operating room anesthesia, patients need to wake up quickly and be aware without untoward effects including respiration depression and drowsiness. Therefore, the goal of sedation in the present study was to limit the RSS score to 2 or 3 . According to the present study, anesthesia with sevoflurane is one of the best choices.

Propofol has been demonstrated to produce a higher incidence of apnea, with a duration $>30 \mathrm{sec}$, which exposes the patient to the risks of a decrease in $\mathrm{SpO}_{2}$ (43). As brain damage related to respiratory events is the leading cause of morbidity 
in anesthesia-related events, the safety of anesthesia is critical. Research has demonstrated that propofol is associated with a 9.7\% incidence of apnea $(44,45)$.

Additionally, the present study demonstrated that the incidence of dizziness in group $\mathrm{S}$ was significantly lower than that in group P. However, due to side effects such as PONV and postoperative delirium, sevoflurane was disliked by some anesthetists. In the present study, no significant difference was observed between the occurrence of PONV or postoperative delirium existed between the two groups. There is a high incidence of PONV in gastrointestinal surgery, and it is known that propofol may reduce the occurrence of PONV $(46,47)$. Research has indicated that sevoflurane may effectively decrease awareness during surgery (48). However, the present study did not show any significant difference in the occurrence of $\mathrm{PONV}$, the occurrence of postoperative delirium or awareness during the surgery between the two groups, maybe because the sample was not large enough.

The results of the present study demonstrated that, when compared with use of propofol, compound use of sevoflurane and remifentanil may induce less side effects, including blood fluctuation, respiration depression, dizziness and awareness of patients. Therefore, the anesthetists and patients were much more satisfied with the sevoflurane anesthetic in the present study. In the present study, 3 patients were excluded because of reflux aspiration and hemorrhage shock. This occurred prior to induction in 1 patient and during the surgery in the other 2 patients. Gastrointestinal bleeding is a major risk that may occur at any time for patients undergoing EVL and EVS. Therefore, it is essential to minimize the risks of perioperative reflux and aspiration, such as the preparation of the aspirator or suction apparatus and rapid sequence intubation. If this occurred, it should be ensured that the airway is unobstructed and then the hemorrhage shock should be dealt with.

In conclusion, the present study preliminarily demonstrated that endotracheal intubation and sevoflurane inhalation anesthesia are more effective and safer for patients undergoing EVL and EVS compared with propofol anesthesia. Sevoflurane greatly reduced BP fluctuation and reflux-aspiration risk. In terms of recovery of postoperative respiration and consciousness, sevoflurane inhalation and remifentanil anesthetic regimens have more advantages, and may be the ideal anesthetic drugs and methods to use for EVL and EVS surgery. However, as the sample size of the present study was not large, further research is required to further verify the results of the present experiment.

\section{Acknowledgements}

The present study was supported by grants from the Natural Science Foundation of China [grant nos. 81401574 (received by Huimin Liu) and NSFC81471844 (received by Zhongyuan Xia)].

\section{References}

1. Chinese society of hepatology, Chinese medical association; Chinese society of infectious diseases, Chinese medical association, Hou JL and lai W: The guideline of prevention and treatment for chronic hepatitis B: A 2015 update. Zhonghua Gan Zang Bing Za Zhi 23: 888-905, 2015.
2. Jian-gao F; Chinese Liver Disease Association: Guidelines for management of nonalcoholic fatty liver disease: An updated and revised edition. Zhonghua Gan Zang Bing Za Zhi 18: 163-166, 2010.

3. Ding S, Wang J and Lu F: Currrent status of research on hepatitis $\mathrm{B}$ and its prevention and treatment in China. Chuan Ran Bing Xin Xi 26: 369-372, 2013 (In Chinese).

4. European association for the study of the liver: EASL clinical practice guidelines: Management of chronic hepatitis B virus infection. J Hepatol 57: 167-185, 2012.

5. Yang C, Qin B, Yuan Z, Chen L and Zhou HY: Meta-analysis of prophylactic entecavir or lamivudine against hepatitis B virus reactivation. Ann Hepatol 15: 501-511, 2016.

6. Gado A, Ebeid B, Abdelmohsen A and Axon A: Predictors of mortality in patients with acute upper gastrointestinal hemorrhage who underwent endoscopy and confirmed to have variceal hemorrhage. Alexandria J Med 51: 295-304, 2015.

7. Haq I and Tripathi D: Recent advances in the management of variceal bleeding. Gastroenterol Rep (Oxf) 5: 113-126, 2017.

8. Brunner F, Berzigotti A and Bosch J: Prevention and treatment of variceal haemorrhage in 2017. Liver Int 37 (Suppl 1): S104-S115, 2017.

9. Spaander MC, Darwish Murad S, van Buuren HR, Hansen BE, Kuipers EJ and Janssen HL: Endoscopic treatment of esophagogastric variceal bleeding in patients with noncirrhotic extrahepatic portal vein thrombosis: A long-term follow-up study. Gastrointest Endosc 67: 821-827, 2008.

10. Lahbabi M, Mellouki I, Aqodad N, Elabkari M, Elyousfi M, Ibrahimi SA and Benajah DA: Esophageal variceal ligation in the secondary prevention of variceal bleeding: Result of long term follow-up. Pan Afr Med J 15: 3, 2013.

11. Sauerbruch T, Appenrodt B, Schmitz V and Spengler U: The conservative and interventional treatment of the complications of liver cirrhosis: Part 2 of a series on liver cirrhosis. Dtsch Arztebl Int 110: 126-132, 2013.

12. Ryan BM, Stockbrugger RW and Ryan JM: A pathophysiologic, gastroenterologic, and radiologic approach to the management of gactric varices. Gastroenterology 126: 1175-1189, 2004.

13. Rahimzadeh P, Safari S, Faiz SH and Alavian SM: Anesthesia for patients with liver disease. Hepat Mon 14: e19881, 2014.

14. Song JC, Sun YM, Yang LQ, Zhang MZ, Lu ZJ and Yu WF: A comparison of liver function after hepatectomy with inflow occlusion between sevoflurane and propofol anesthesia. Anesth Analg 111: 1036-1041, 2010.

15. Tao KM, Yang LQ, Liu YT, Tao Y, Song JC, Wu FX and Yu WF: Volatile anesthetics might be more beneficial than propofol for postoperative liver function in cirrhotic patients receiving hepatectomy. Med Hypotheses 75: 555-557, 2010.

16. Saito K, Kodama Y,Ono S, Maida C, Fujimura A and Miyamoto E: Reliability of Japanese clinical trials estimated from GCP audit findings. Int J Clin Pharmacol Ther 46: 415-420, 2008.

17. Takagi K, Yagi T, Yoshida R, Shinoura S, Umeda Y, Nobuoka D, Kuise T, Watanabe N and Fujiwara T: Sarcopenia and American society of anesthesiologists physical status in the assessment of outcomes of hepatocellular carcinoma patients undergoing hepatectomy. Acta Med Okayama 70: 363-370, 2016.

18. Kim TK, Niklewski PJ, Martin JF, Obara S and Egan TD: Enhancing a sedation score to include truly noxious stimulation: The extended observer's assessment of alertness and sedation (EOAA/S). Br J Anaesth 115: 569-577, 2015.

19. Bell JK, Laasch HU, Wilbraham L, England RE, Morris JA and Martin DF: Bispectral index monitoring for conscious sedation in intervention: Better, safer, faster. Clin Radiol 59: 1106-1113, 2004.

20. Barakat AR, Sutcliffe N and Schwab M: Effect site concentration during propofol TCI sedation: A comparison of sedation score with two pharmacokinetic models. Anaesthesia 62: 661-666, 2007.

21. Aicher B, Peil H, Peil B and Diener HC: Pain measurement: Visual Analogue Scale (VAS) and Verbal Rating Scale (VRS) in clinical trials with OTC analgesics headache. Cephalalgia 32: 185-197, 2012.

22. Chang B and Urman RD: Non-operating room anesthesia: The principle of patient assessment and preparation. Anesthesiol Clin 34: 223-240, 2016.

23. Feng AY, Kaye AD, Kaye RJ, Belani K and Urman RD: Novel propofol derivatives and implications for anesthesia practice. J Anaesthesiol Clin Pharmacol 33: 9-15, 2017.

24. Yağan Ö, Taş N, Küçük A, Hancı V and Yurtlu BS: Haemodynamic responses to tracheal intubation using propofol, etomidate and etomidate-propofol combination in anaesthesia induction. J Cardiovasc Thorac Res 7: 134-140, 2015. 
25. Lovett P, Gómez V, Hodge DO and Ladlie B: Propofol versus midazolam/fentanyl sedation for colonoscopy in the elderly patient population. J Perianesth Nurs 32: 210-214, 2017.

26. Eger EI II: New inhaled anesthetics. Anesthesiology 80: 906-922, 1994.

27. De Hert S and Moerman A: Sevoflurane. F1000Res 4: 626, 2015.

28. Lawton BK, Brown NJ, Reilly CS and Brookes ZL: Role of L-type calcium channels in altered microvascular responses to propofol in hypertension. Br J Anaesth 108: 929-935, 2012.

29. Isik A, Taydas E, Ulukaya S, Balcioglu T, Aydin U and Kilic M: Additive effect of propofol for attenuation of hypertension in a patient with undiagnosed phaeochromocytoma. Eur J Anaesthesiol 24: 561-562, 2007.

30. Onk D, Akarsu Ayazoğlu T, Onk OA, Aksüt M, Günay M, Turmen K, Özensoy A, Yazici Ersoy C and Coban A: Comparison of TIVA and Desflurane added to a subanaesthetic dose of propofol in patients undergoing coronary artery bypass surgery: Evaluation of Haemodynamic and stress hormone changes. Biomed Res Int 2016: 3272530, 2016.

31. Haq I and Tripathi D: Recent advances in the management of variceal bleeding. Gastroenterol Rep (Oxf) 5: 113-126, 2017.

32. Meng QT, Cao C, Liu HM, Xia ZY, Li W, Tang LH, Chen R, Jiang M, Wu Y, Leng Y and Lee CC: Safety and efficacy of etomidate and propofol anesthesia in elderly patients undergoing gastroscopy: A double-blind randomized clinical study. Exp Ther Med 12: 1515-1524, 2016.

33. Kim YS, Lim BG, Kim H, Kong MH and Lee IO: Effects of propofol or desflurane on post-operative spirometry in elderly after knee surgery: A double-blind randomised study. Acta Anaesthesiol Scand 59: 788-795, 2015.

34. Law-Koune JD, Raynaud C, Liu N, Dubois C, Romano M and Fischler M: Sevoflurane-remifentanil versus propofol-remifentani anesthesia at a similar bispectral level for off-pump coronary artery surgery: No evidence of reduced myocardial ischemia. J Cardiothorac Vasc Anesth 20: 484-492, 2006.

35. Yao YT and Li LH: Sevoflurane versus propofol for myocardial protection in patients undergoing coronary artery bypass grafting surgery: A meta-analysis of randomized controlled trials. Chin Med Sci J 24: 133-141, 2009.

36. Isabel C, Calvet D and Mas JL: Stroke prevention. Presse Med 45: e457-e471, 2016.

37. Godet G, Watremez C, El Kettani C, Soriano C and Coriat P: A comparison of sevoflurane, target-controlled infusion propofol, and propofol/isoflurane anesthesia in patients undergoing carotid surgery: A quality of anesthesia and recovery profile. Anesth Analg 93: 560-565, 2001.
38. Imanaka N, Nakasuji M, Nomura M, Higuchi M, Nakamura M, Tanaka $\mathrm{M}$ and Kawashima H: Hypertension with tachycardia caused by propofol during induction of general anesthesia. Masui 58: 652-654, 2009 (In Japanese)

39. Kanaya N, Hirata N, Kurosawa S, Nakayama M and Namiki A: Differential effects of propofol and sevoflurane on heart rate variability. Anesthesiology 98: 34-40, 2003.

40. Dazzani F, Micati M, Caraceni P, Drago GM, Domenicali M, Pacilli P, Tomassetti V, Gelonesi E, Trevisani F and Bernardi M: Transthoracic electrical bioimpedance: A non-invasive technique for the evaluation of the haemodynamic alterations in patients with liver cirrhosis. Dig Liver Dis 37: 786-792, 2005.

41. Pinzani M, Rosselli M and Zuckermann M: Liver cirrhosis. Best Pract Res Clin Gastroenterol 25: 281-290, 2011.

42. Delgado-Herrera L, Ostroff RD and Rogers SA: Sevoflurance: Approaching the ideal inhalational anesthetic. A pharmacologic, pharmacoeconomic, and clinical review. CNS Drug Rev 7: 48-120, 2001.

43. Capasso R, Rosa T, Tsou DY, Nekhendzy V, Drover D, Collins J, Zaghi S and Camacho M: Variable findings for drug-indudced sleep endoscopy in obstructive sleep apnea with propofol versus dexmedetomidine. Otolaryngol Head Neck Surg 154: 765-770, 2016.

44. Capasso R, Rosa T, Tsou DY, Nekhendzy V, Drover D, Collins J, Zaghi $\mathrm{S}$ and Camacho M: Variable findings for drug-induced sleep endoscopy in obstructive sleep apnea with propofol versus dexmedetomidine. Otolaryngol Head Neck Surg 154: 765-770, 2016.

45. Kuyrukluyildiz U, Binici O, Onk D, Ayhan Celik S, Torun MT, Unver E, Ozcicek A and Alagol A: Comparison of dexmedetomidine and propofol used for drug-induced sleep endoscopy in patients with obstructive sleep apnea syndrome. Int J Clin Exp Med 8: 5691-5698, 2015.

46. Mtsuura $\mathrm{H}$, Inoue $\mathrm{S}$ and Kawaguchi M: The risk of postoperative nausea and vomiting between surgical patients received propofol and sevoflurane anesthesia: A matched study. Acta Anaesthesiol Taiwan 54: 114-120, 2016.

47. Çaparlar CÖ, Özhan MÖ, Süzer MA, Yazicioğlu D, Eşkin MB, Şenkal S, Caparlar MA, Imren EÖ, Atik B and Cekmen N: Fast-track anesthesia in patients undergoing outpatient laparoscopic cholecystectomy: Comparison of sevoflurane with total intravenous anesthesia. J Clin Anesth 37: 25-30, 2017.

48. Ishii K, Makita T, Yamashita H, Matsunaga S, Akiyama D, Toba K, Hara K, Sumikawa K and Hara T: Total intravenous anesthesia with propofol is associated with a lower rate of postoperative delirium in comparison with sevoflurane anesthesia in elderly patients. J Clin Anesth 33: 428-431, 2016. 